\title{
Influence of Information and Communication Technology and Entrepreneurship Education on Business Interest
}

\author{
D S Soegoto ${ }^{1}$, E Hervina $^{2 *}$ \\ \{ $\underline{\text { dedissoegoto@email.unikom.ac.id }}^{1}$, $\underline{\text { ehervina@mahasiswa.unikom.ac.id }}^{2}$ \} \\ Departemen Manajemen, Universitas Komputer Indonesia, Indonesia ${ }^{1}$ \\ Departemen Akuntansi, Universitas Komputer Indonesia, Indonesia ${ }^{2}$
}

\begin{abstract}
The purpose of this research is to determine the progress of information and communication technology and entrepreneurship education in business interest. The technology progress that is so fast could make it easier for everyone to get information, including to create business opportunities. Being supported by the entrepreneurship education will create an interest as well as business opportunities that become increasingly large. This research used a descriptive analysis method to obtain the information needed in the research process. The results of this research indicate that technological progress and entrepreneurship education will have a significant effect on the business interests of students. The results are obtained because people who have been studied entrepreneurship and also interested in the development of information and communication technology will have a greater interest to do business. The application of information technology is very useful in entrepreneurship, for example as a marketing medium, and so on. Hence, ICT and entrepreneurship are two things that interrelated in their implementation. From the results of the research can be settled that technological progress and entrepreneurship education could affect a person's interest in business as well as has a strong desire to create jobs in the future.
\end{abstract}

Keywords: Information, technology, entrepreneurship, business.

\section{Introduction}

According to Haag and Keen, information technology is a set of tools that can help a job with information and perform tasks or work related to information processing. In addition to the role of information technology, the role of the internet is also important in helping a human activity. The Internet is used to manage important components in the supply chain, such as purchasing, inventory management, production scheduling, transportation, customer service, warehousing, and vendor relations [1]. According to Clemons et al. information technology can reduce coordination costs without worrying about increasing the risks associated with transactions, by leading to more outsourcing and companies that are still less vertically integrated [2]. According to Haryanto and Riyanarto, in using technology must always be able to maintain the principles of Information Technology to ensure that important and confidential information can be kept as a secret from those who should not have access to it [3]. According to Kolko et al., Efficient information management will benefit the institution or company. However, everyone's understanding of how culture, policy, and infrastructure affect the pattern 
of Internet development [4]. According to Mark and Daniel, information technology will be used with various desired consequences for users, organizations, and other interested parties [5]. Zimmerer explained that entrepreneurship is a process in applying the creativity and innovation that is inside to solve a problem and can find opportunities to improve business life [6]. Cope believes that theoretical understanding of entrepreneurial learning is very important for every individual because, through the entrepreneurial learning process, prospective entrepreneurs can grow and develop. In entrepreneurship education contained entrepreneurial values taught by lecturers. These values have an independent nature, creativity, risk, courage to take, act, oriented, leadership, hard work, and honesty [7]. Holcomb et all defines entrepreneurial learning as a person's process to gain new knowledge from various experiences or observations of other people's behavior, actions and consequences, make intuitive or heuristic conclusions because there is always environmental uncertainty and inconsistent information, and manage knowledge that has been obtained by connecting with existing knowledge structures [8]. Vein Vallerand et all defines passion or interest as a strong tendency towards an activity or hobby that is liked by someone and is considered important, where the investment of time and energy is a pleasure [9]. Passion in entrepreneurship is an intense positive emotion that can cause motivational effects to stimulate the minds of entrepreneurs to be able to overcome obstacles and encourage their involvement in entrepreneurial activities [10].

The purpose of this research is to find out how the influence of information and communication technology (ICT) as well as entrepreneurial education in fostering someone's interest within doing online business. This research used descriptive analysis method to obtain information needed in the research process. The results are obtained because people who have been studied entrepreneurship and also interested in the development of information and communication technology will have a greater interest to do business.

\section{Method}

This study used a descriptive analysis method to find out how the influence can be generated from the knowledge that is possessed related to information and communication technology along with entrepreneurship on the interest in doing online business. Previous research related to the impact of ICT and entrepreneurial education on interest in doing business. We use WordPress and IDwebhost as research objects, to analyze and provide an implementation of starting a business with the internet as an intermediary so that it can find out how much it influences ICT and entrepreneurial knowledge in creating interest while doing online business.

\section{Results and Discussion}

Nowadays, we can start and build a business easily by utilizing technology and information improvements as a tool to support the start of business. Some tools that can be used as information and communication media for business can be in the form of applications, websites, blogs and others that can facilitate business processes both for purchasing activities and sales activities in the form of goods or services that can be done quickly by conducting business activities by online. 
Now the online-based business has become a very important needs to support the development and progress of a business. Besides, an online business makes it easier for us to market and sell our products without spending a lot of money to advertise it on television or to load advertisements in newspapers, of course, the costs incurred for advertising these products or services are quite expensive. By using a website or blog to do business, it will save more money in building a business especially for beginners like students who want to do business.

A website for an online business can help and facilitate the running of business activities, especially easy to access information by all people connected to the internet throughout the world. So that the products marketed using online websites will be quickly known and can quickly attract the attention and interest of people to choose and buy a product or service offered on the website that has been created. Several things must be done in starting an online business, especially for beginners who have an interest in doing business and also know about entrepreneurship. We can start the business by utilizing the advancement of information and communication technology today, such as the WordPress platform that provides features and menus to support online business. Besides being free and easy to use, another advantage of this platform is that the number of users has reached more than 1 million active users, so this platform has been widely known and trusted by people around the world. As a beginner who wants to do business, we can start by creating a website or blog to offer the expertise or products we have.

The following are some steps that can be done by a beginner who wants to do business by utilizing and creating a website using the WordPress platform, namely:

\subsection{Preparing Domain and Hosting Name \\ 3.1.1 Domain}

The first step that must be done is to prepare a domain name that will be used on the website, for example, such as www.your-company.com. Because we will create a premium website, then we have to buy a domain name that will be used. We can buy it from the domain name or registration service providers. For example, we can visit sites like idwebhost.com, masterweb.net, rumahweb.co.id, and the like which are providers of domain names from local companies. Or we can also visit sites like godaddy.com, namecheap.com as well as sites that provide domain names from overseas companies.

\subsubsection{Hosting}

In the next step, we need hosting to associate it with the domain. Which serves as a means to store all data coming from our website, such as text, images, videos and so on. We can get this hosting with a rental system, with a capacity that suits the needs of each tenant. To be easier, you should purchase a domain and hosting leases done at the same time from one service provider. Look at Figure 1 below. 


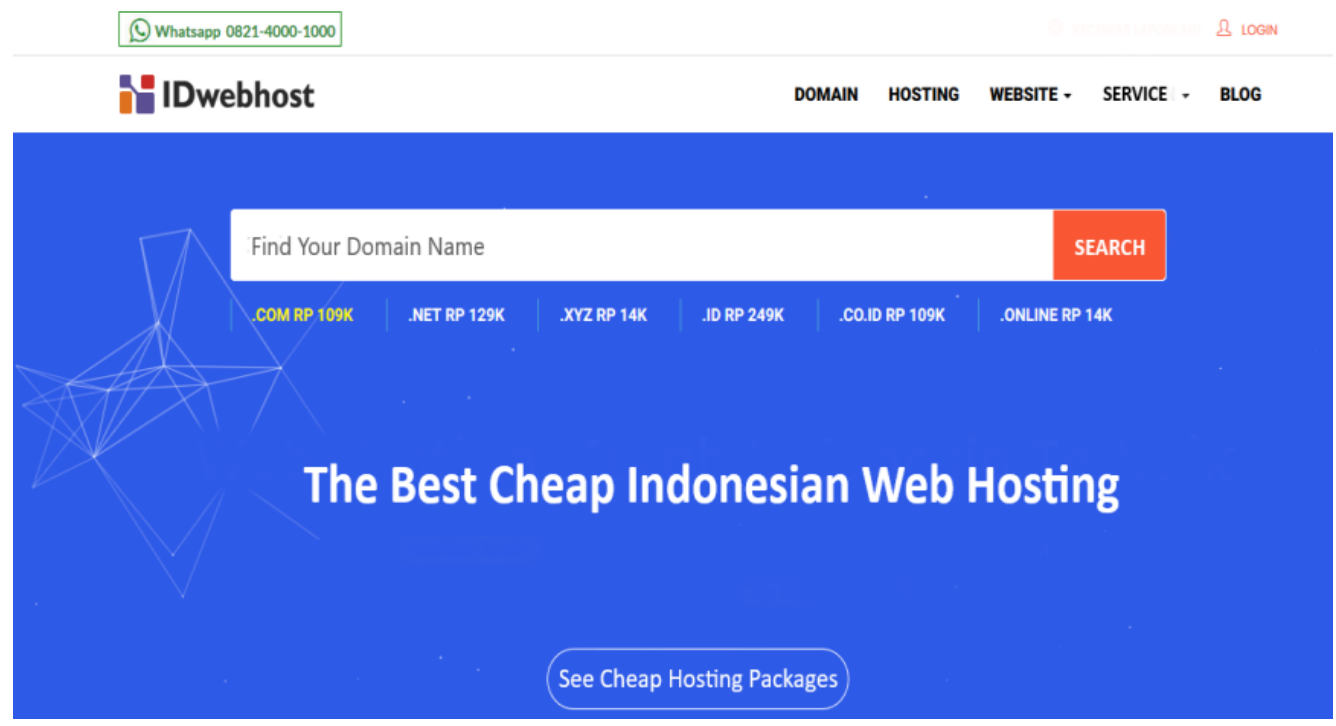

Fig 1. Idwebhost Domain.

\subsection{Preparing Website Creation Software (CMS)}

After we have a domain and also hosting, the next step is to install software to create a website on our hosting. Previously, the software or CMS that will be discussed in this study is to use WordPress. Why use WordPress? Because WordPress is one of the most popular software that is used today to create sites such as websites, business profiles, blogs, and online stores around the world. WordPress is widely chosen and used by entrepreneurs because it has features that are easy to use and also sophisticated. Look at Figure $\mathbf{2}$ below.

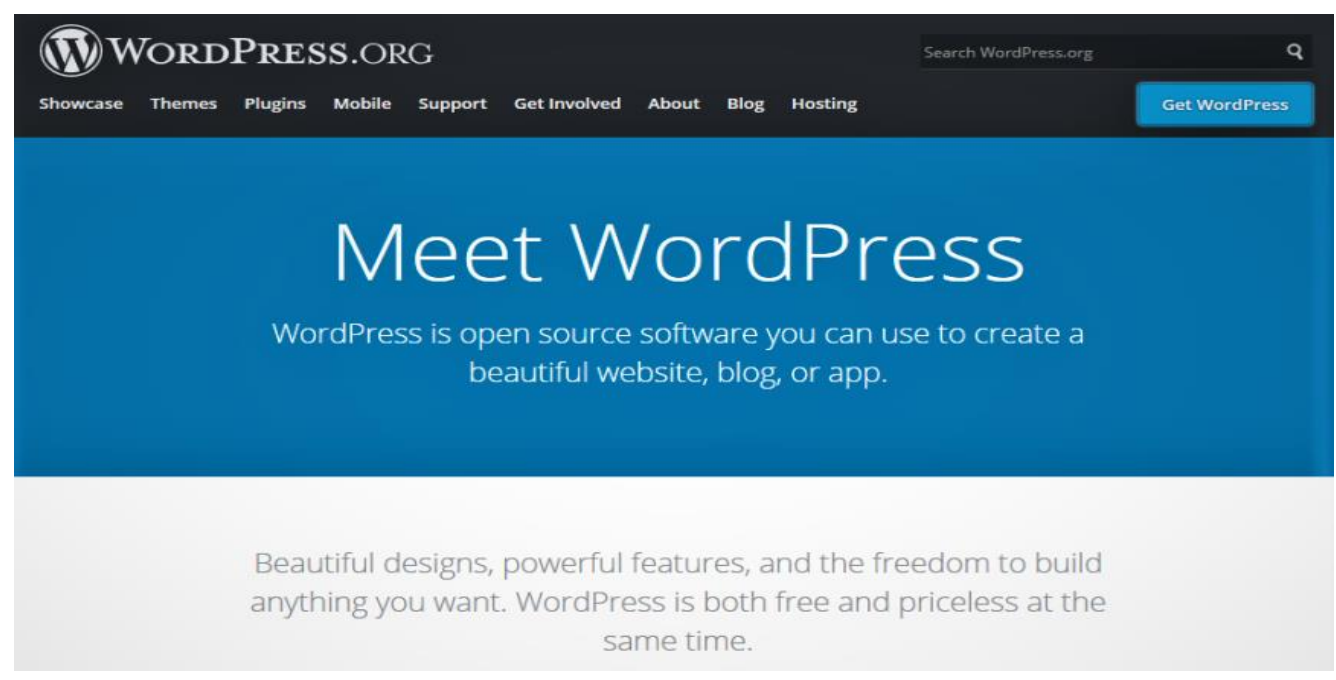

Fig 2. WordPress Software. 
The step below is to install WordPress on our hosting:

\subsection{Login to Cpanel}

After we rented a hosting we will be given an access to the c-panel or also be called the control panel to make arrangements for the website support program. We can access it by typing namadomain.com/cpanel in our browser so that we can enter the website. Next, we have to fill in the password and username that we have previously obtained from the hosting provider. Look at Figure 3 below.

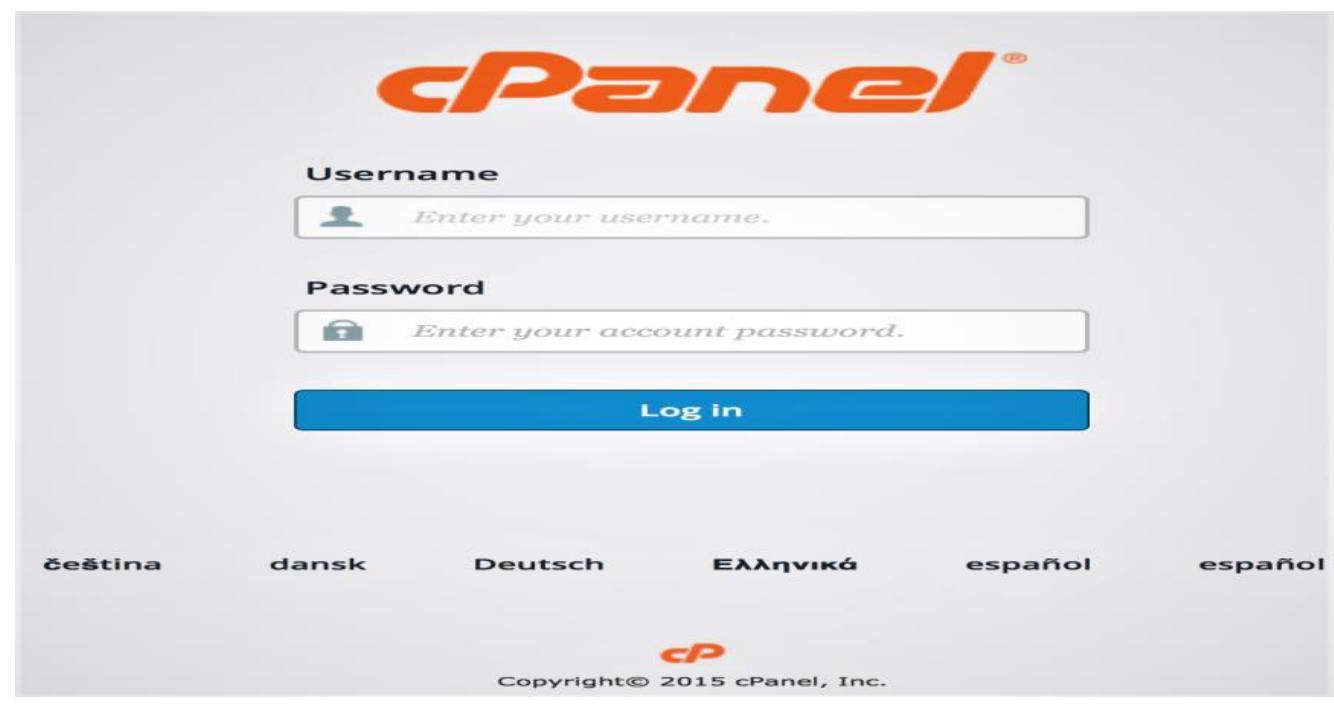

Fig 3. CPanel/Control Panel.

\subsection{Install WordPress Via Softaculous}

After successfully logging in to the c-panel, we have to look for the "Software and Service" section and select Softaculous. Softaculous is an auto-installer program that is provided by the hosting so that it can facilitate us in installing WordPress. See in Figure 4 below.

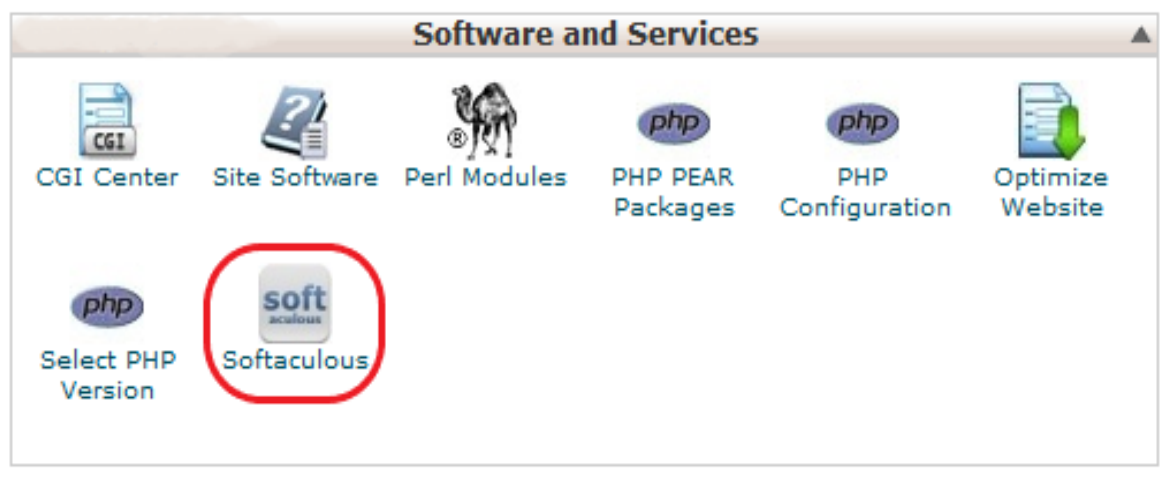

Fig 4. Softaculous in Software/Service 


\subsection{Install WordPress}

In softaculous we will immediately find lots of CMS or software that can be used to create a website. Wordpress is one of them, to start the installation of WordPress we click install. We are required to fill in some data before the installation process starts. By filling in the password and username, we will be able to log in to the WordPress admin. Then we click install to be able to continue the installation process and wait until the installation process is complete and successful. Look at Figure 5 below.

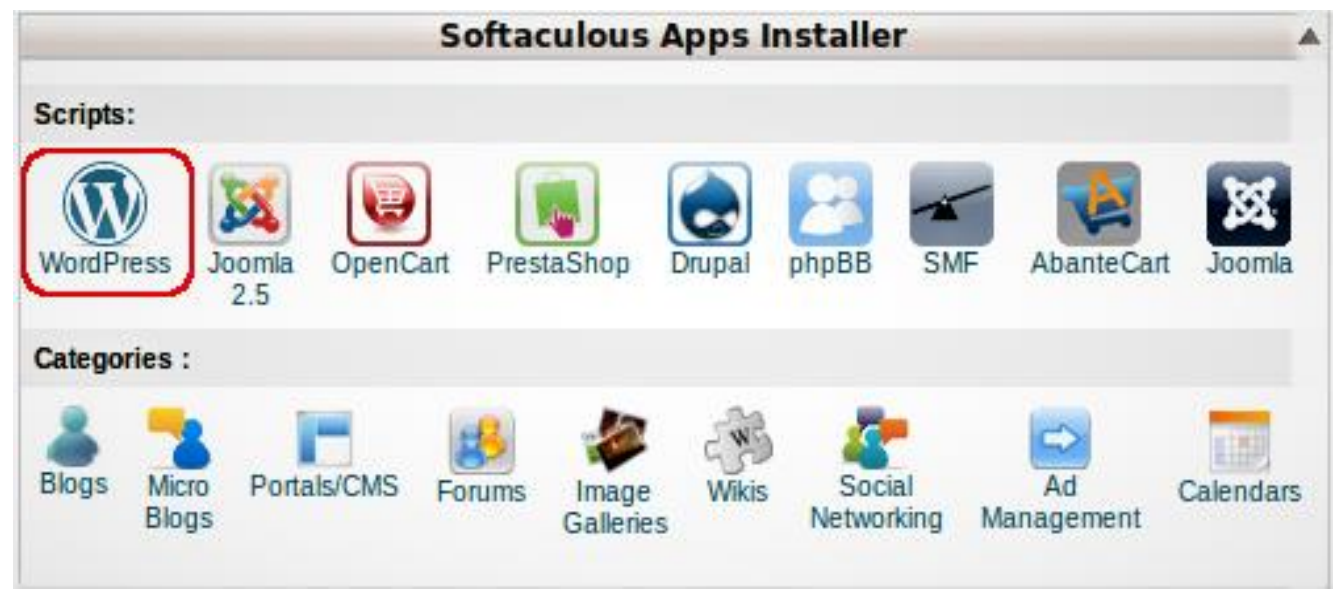

Fig 5. Install WordPress in Softaculous

At this stage, we have finished installing WordPress on our website, then by only displaying the information "Under Maintenance" then our website can be accessed. Actually, the steps that must be taken in making a website for business and online stores are the same, only on the use of themes or templates for different website views. The steps are as follows:

\subsection{Managing Website Views}

The next step to make the website look is by accessing the WordPress admin page that we have installed earlier, the way is by accessing the namadomain.com/wp-admin page in our browser. Then we are required to fill in the WordPress admin password and username that we created earlier. Look at Figure 6 below. 


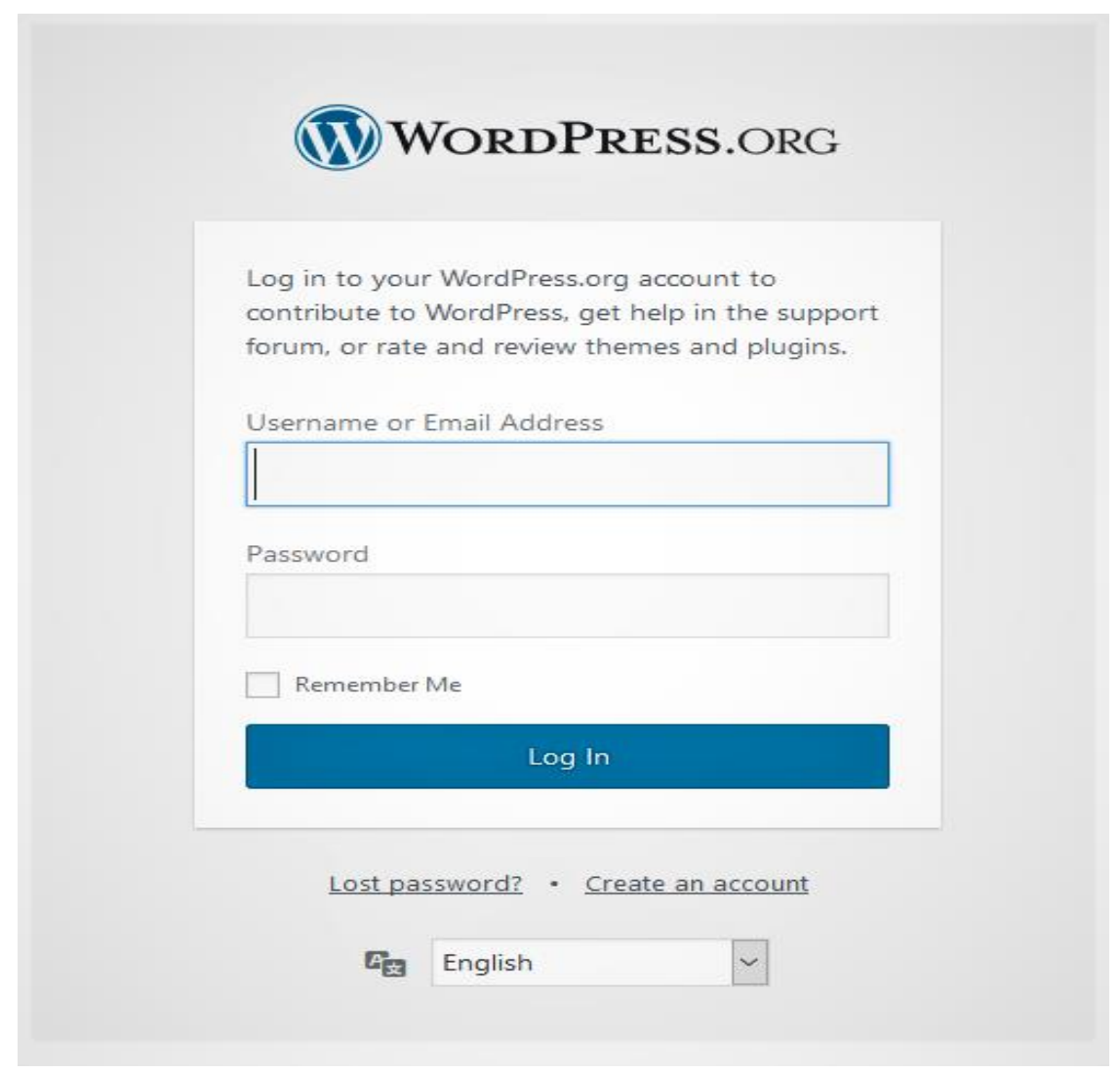

Fig 6. WordPress Admin Display.

After we are on the WordPress Dashboard page, here are various activities to create a website. Starting from the display settings, page creation, posting and so on. The first step to take is to choose a theme that is available and free from WordPress. But if we want a more interesting and unique theme, we can choose a paid theme from the theme makers. After that, we can see the column on the left and select the "Appearance" then "theme". There we will be given a variety of choices from the theme display that can be used on our website, we just choose a theme according to our needs or desires. We can even see the demo first before installing the theme by selecting "review". If the desired theme has been selected then click install. Look at Figure 7 below. 


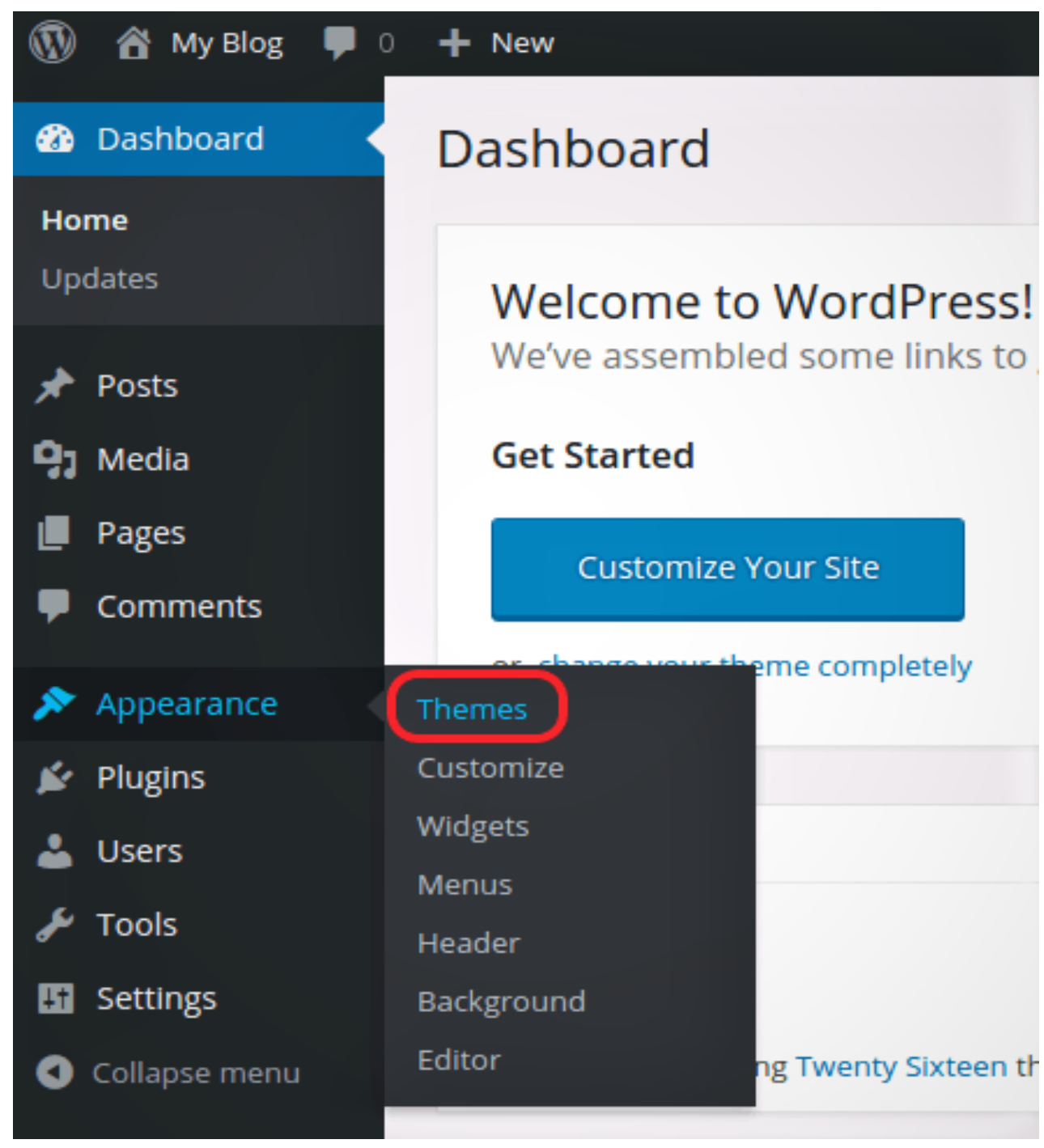

Fig 7. WordPress Dashboard Display.

We can check and ensure the appearance of the website that has been installed by directing the mouse cursor on the top left of the dashboard then selecting the home icon and clicking visit site.

\subsection{Creating Pages and Posts}

After we finish creating the website display, then we can create a page by selecting the "pages" menu then "add new" in the WordPress dashboard. To write the title that we will use as the name of the page, we can see the top column. In general, a business website has pages like About Us, contacts, products and other information. Then we can also add text, images or videos that will be used as the contents of the page that was created. Next is to make the post done the 
same way as creating a page. It's just that this post serves to create articles or lists of products from our business. Each post is clarified according to the categories needed. Look at Figure 8 below.

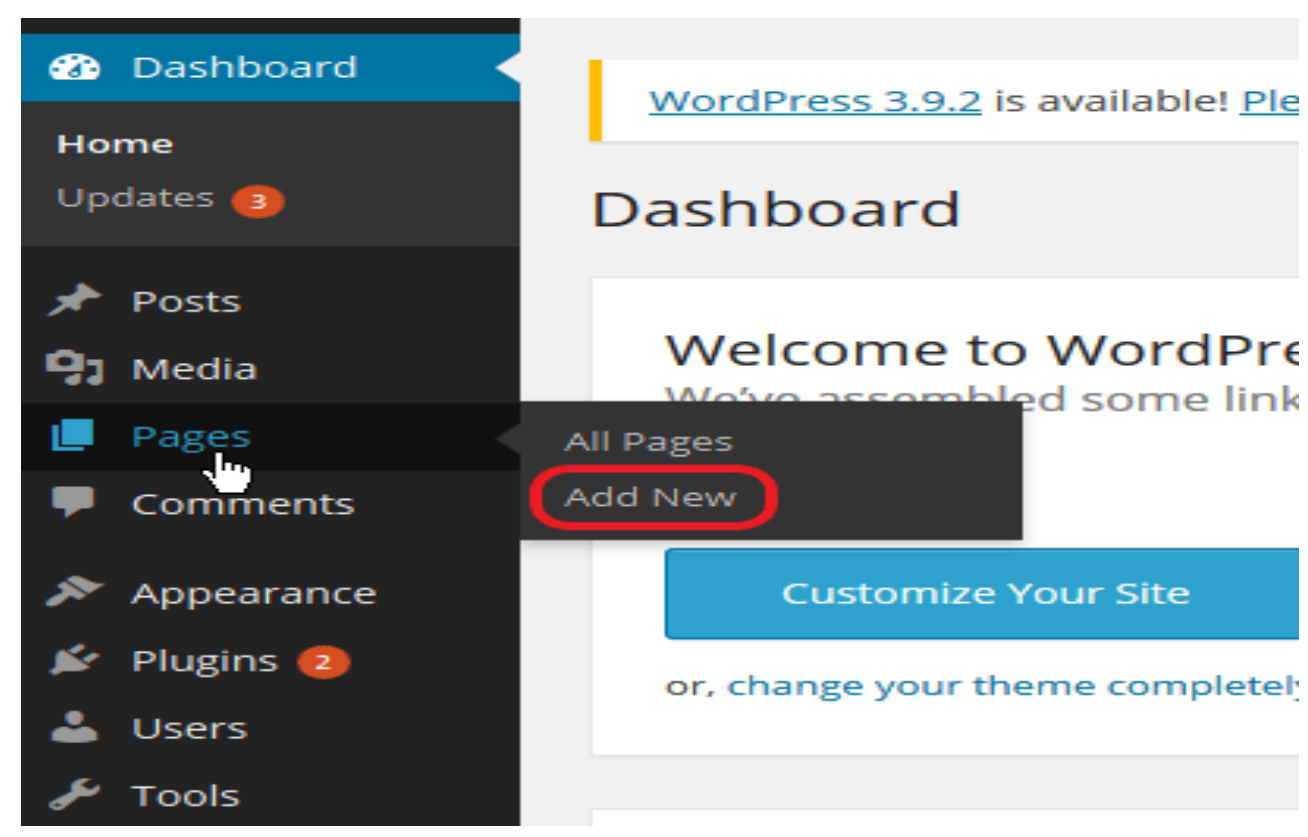

Fig 8. Add New to the WordPress Dashboard.

After the contents on the page and post are made, we can immediately publish it on our website by selecting "publish" in the right hand column. Those are some steps and ways to create a website for business purposes. We are allowed to be creative on our website by adding logos, changing colors and choosing new themes and the like to make our website look more attractive. Using a website for business can increase the credibility of small businesses, save costs, maintain relationships by always connecting with customers, easy to access, can reach a wider target market even to the world, product and service catalog facilities, can save time and improve service to customers. Therefore, the various facilities that offered will further foster interest in entrepreneurship for beginners, especially for students. With the knowledge possessed about entrepreneurial technology and knowledge, the desire to do business that has been planned in advance can be realized and implemented as expected, because of the ease provided by the development of technology, namely the existence of online business today.

\section{Conclusion}

The progress of information and communication technology has had a huge impact on economic development and business development in the world. Likewise, the growing interest of students in entrepreneurship cannot be separated from the role of education that has provided knowledge about business and technology. Those who have been studied and understood the 
knowledge of business and ICT will be more capable and brave in starting as well as running a business. With a platform that provides websites for doing business online, it can provide benefits and convenience for anyone who does business using the platform. The online business also has a significant impact on business development and the smooth relationship between entrepreneurs and their customers, so there is no reason for beginners to be afraid and doubtful in starting a business.

\section{Acknowledgement}

The author would like to thank the parties who have helped and guided in the preparation of this scientific paper. Especially to the rector of the Universitas Komputer Indonesia, Dr. Ir. Eddy Soeryanto Soegoto and his team, so that this paper can be completed properly and on time.

\section{References}

[1] Lancioni, R. A., Smith, M. F., \& Oliva, T. A.: The role of the Internet in supply chain management. Industrial Marketing Management, 29(1), pp. 45-56. (2000).

[2] Clemons, E. K., Reddi, S. P., \& Row, M. C.: The impact of information technology on the organization of economic activity: The "move to the middle" hypothesis. Journal of management information systems, 10(2), pp. 9-35. (1993).

[3] Tanuwijaya, H., \& Sarno, R.: Comparation of COBIT maturity model and structural equation model for measuring the alignment between university academic regulations and information technology goals. IJCSNS, 10(6), pp. 67-80. (2010).

[4] Kolko, B. E., Wei, C. Y., \& Spyridakis, J. H.: Internet use in Uzbekistan: Developing a methodology for tracking information technology implementation success. Information Technologies and International Development, 1(2), pp. 1-15. (2003).

[5] Cardon, M. S., Wincent, J., Singh, J., \& Drnovsek, M.: The Nature and Experience of Entrepreneurial Passion. Academy of Management Review, 34(3), pp. 511-532. (2009).

[6] Soegoto, Eddy Soeryanto.: Entrepreneurship: Menjadi Pebisnis Ulung. Jakarta: Elex Media Komputindo. (2014).

[7] Cope, J.: Toward A Dynamic Learning Perspective of Entrepreneurship. Entrepreneurship Theory and Practice, 29(4), pp. 373-97. (2005).

[8] Holcomb, Ireland, Holmes., \& Hitt.: Architecture of Entrepreneurial Learning: Exploring The Link among Heuristics, Knowledge, and Action Entrepreneurship. Theory and Practice, 33(1), pp. 167-192. (2009).

[9] Vallerand, Mageau, Ratelle, Leonard, Blanchard, Kostner., \& Gagne.: Les Passion de l'Ame: On Obsessive and Harmonious Passion. Journal of Personality and Social Psychology, 85(4), pp. 756-767. (2003).

[10] Markus, M. L., \& Robey, D.: Information technology and organizational change: causal structure in theory and research. Management science, 34(5), pp. 583-598. (1988). 